\title{
Effect of Lumbar Cistern Drainage Combined with Nimodipine on Cerebral Vasospasm after Intracranial Aneurysm Intervention
}

K. XIA*AND Q. CHEN

Department of Neurosurgery, The Second People's Hospital of Liaocheng, Liaocheng, 252600, China

Xia and Chen: Effect of Lumbar Cistern Drainage Combined with Nimodipine on Cerebral Vasospasm 
The aim of the present study was to observe and analyze the effect of lumbar cistern drainage combined with nimodipine on cerebral vasospasm after intracranial aneurysm intervention. About 180 patients who underwent intracranial aneurysm intervention in the Second People's Hospital of Liaocheng were enrolled as research subjects. They were randomly divided into the research group and the control group, each containing 90 patients. The control group was subjected to combined therapy of nimodipine with intermittent lumbar puncture to release cerebrospinal fluid; while the research group was subjected to combined therapy of lumbar cistern drainage and nimodipine. The therapeutic effect in both groups of patients was observed and compared. The incidence rate of cerebral vasospasm was significantly lower in the research group when compared to the control group. The cerebrospinal fluid pressure and erythrocyte count on postoperative days 4,8 and 12 was significantly lower in the research group. Both groups showed significant improvement after treatment, but the improvement in research group was more pronounced. By observing the degree of neurological defects between the 2 groups, the national institutes of health stroke scale score of the research group had significant advantages compared to that of the control group. For patients with intracranial aneurysm interventional therapy, the application of lumbar cistern drainage combined with nimodipine could achieve better results with greater safety.

Key words: Lumbar cistern drainage, nimodipine, intracranial aneurysm intervention, cerebral vasospasm

Intracranial aneurysm is basically the abnormal protrusion of cerebral artery wall, which is a common factor leading to spontaneous subarachnoid hemorrhage. Currently, there has not been a completely unified understanding of the causes of intracranial aneurysm disease. However, congenital aneurysm accounts for a larger proportion in patients. The disease can occur at any age and is most common among patient of age 40-60 $\mathrm{y}^{[1-3]}$. Most intracranial aneurysm occur in the anterior part of the cerebral artery circulus, characterized by spontaneous cerebral hemorrhage, cerebral vasospasm, oculomotor paralysis and other focal symptoms ${ }^{[4]}$. The rupture of arterial aneurysm is often a leading cause of severe symptoms and even death. This disease can seriously affect the normal quality of life and work of patients. It is also one of the important diseases that threaten the safety of patients, which is greater concern.

Intracranial aneurysms (fig. 1) are mostly caused by local congenital defects in the cerebral artery wall and increased intracavitary pressure. Hypertension, cerebral arteriosclerosis, vasculitis are related to the occurrence and development of aneurysm. Cerebral aneurysms are more common in the bifurcation of the basilar artery. Interventional treatment of intracranial aneurysm is the main treatment method, which can effectively control local hemorrhage and promote nerve functional repair. However, cerebral vasospasm is very easy to occur after intracranial aneurysm intervention, which is also an important factor leading to the death of patients. This study investigated the effect of lumbar cistern drainage combined with nimodipine on cerebral vasospasm after intracranial aneurysm intervention, which provides a reference for clinical treatment and promote the rehabilitation of patients.

One hundred and eighty patients with intracranial aneurysms who had been treated in the Second People's Hospital of Liaocheng from January, 2015 to June, 2018 were enrolled as research subjects. The inclusion criteria were, all those patients with confirmed intracranial aneurysm (fig. 1) after clinically relevant examination; all patients who were indicated for the intracranial aneurysm interventional therapy and all patients with good treatment compliance, voluntarily joined the study and signed the informed consent. The exclusion criteria were patients with serious organic diseases, mental disorders, coagulation system diseases and low degree of cooperation. The patients were divided into the research group and the control group, each containing 90 subjects. In the research group, there were 55 males and 35 females, aged between 18 and $35 \mathrm{y}$ with an average age of $23.7 \pm 0.8 \mathrm{y}$. The control

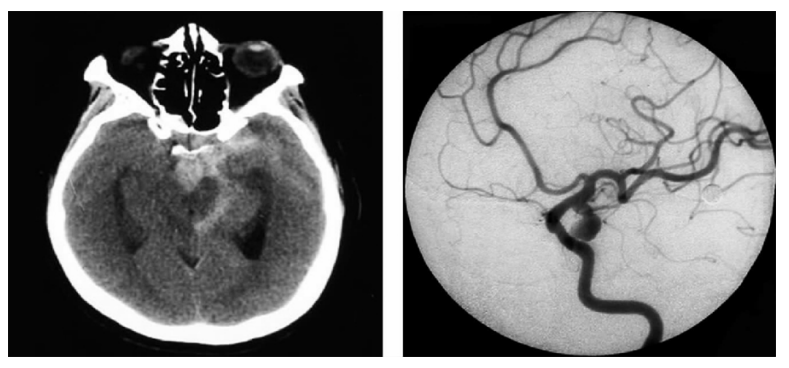

Fig. 1: Image of intracranial aneurysm 
group included 50 males and 40 females, aged from 18 to $33 \mathrm{y}$ (average age $24.6 \pm 1.1 \mathrm{y}$ ). There were significant differences in general data between these 2 groups.

Patients in the control group were treated with conventional symptomatic support. Before the intervention, patients were treated with nimodipine injection $(10 \mathrm{mg} / \mathrm{ml})$, which was diluted to $250 \mathrm{ml}$ with normal saline. After dilution, a microinjection pump was used to deliver the drug intravenously, with an infusion rate of $4.2 \mathrm{ml} / \mathrm{h}$. The administration was maintained for $24 \mathrm{~h}$. After interventional treatment, daily lumbar puncture was performed to release cerebrospinal fluid once a day, with about $30 \mathrm{ml}$ of cerebrospinal fluid being released each time. According to the results of CT examination, the release time of cerebrospinal fluid was strictly controlled. If the CT examination shows that the intracranial hemorrhage has disappeared, releasing of cerebrospinal fluid was stopped.

Patients in the research group were subjected to a combined therapy of lumbar cistern drainage combined with nimodipine, in which the nimodipine therapy was the same as that for control group. In addition, lumbar cistern drainage was carried out according to standard procedure. The patient was allowed to take a comfortable lateral position and $\mathrm{L}_{3-4}$ spine or between $\mathrm{L}_{4-5}$ spine was punctured. A $18 \mathrm{G}$ puncture needle was inserted in to the lumbar cistern, cerebrospinal fluid was observed and allowed to flow into a $15 \mathrm{~cm}$ long epidural tube and the needle was pulled out. The drainage was conducted at a rate of 3 drops per minute and the flow was controlled at around $300 \mathrm{ml}$ for $24 \mathrm{~h}$. Finally, the drainage time was set according to $\mathrm{CT}$ examination results, which is usually set to be around $14 \mathrm{~d}^{[5]}$.

First, the incidence of postoperative cerebral vasospasm in both groups was observed. The evaluation criteria included ${ }^{[6]}$, sudden deterioration after the disease is improved resulting in fever, high blood image and no signs of infection; neurological signs such as hemiplegia, aphasia, agnosia or apraxia; symptoms of increased intracranial pressure such as vomiting, headache and visual papilla; cerebral vasospasm was observed from CT angiography or magnetic resonance angiography. Second, the CSF pressure and erythrocyte count in CSF were measured before and after surgery on days 4,8 and 12. Finally, the degree of neurological defect was evaluated using the National Institute of Health Stroke Scale (NIHSS) score before and after treatment, the higher the degree of neural impairment, the higher the score.

All data were processed and analyzed using the software SPSS21.0. The measurement data was expressed as mean \pm standard deviation and intergroup difference was compared by chi-square; enumeration data was expressed by natural number (n) and percent (\%) and intergroup difference was compared by t. The difference was considered statistically significance when $p<0.05$.

As shown in Table 1, the rate of cerebral vasospasm in the research group was significantly lower than that in control group $p<0.05$. As shown in Table 2, there was no significant difference in NIHSS scores between the two groups before treatment, but after treatment the NIHSS score in research group was significantly higher than that in control group $p<0.05$. As shown in Table 3, after treatment, there was significant improvement in CSF pressure and erythrocyte count in CSF in the research group compared to the control group $p<0.05$. The imaging examination of a certain patient before and after treatment are shown in figs. 2 and 3, respectively.

Currently, the most effective treatment of intracranial aneurysms is interventional surgery. Cerebral vasospasm is a common and serious complication after interventional surgery. Cerebral vasospasm can easily cause severe cerebral perfusion deficiency, secondary ischemic cerebral infarction, aggravate brain injury and pose a threat to patient safety ${ }^{[7,8]}$. After interventional

TABLE 1: COMPARISON OF CEREBRAL VASOSPASM RATE BETWEEN THE TWO GROUPS

\begin{tabular}{lcc}
\hline Group & $\begin{array}{c}\text { Case number } \\
(\mathrm{n})\end{array}$ & $\begin{array}{c}\text { Cerebral vasospasm rate } \\
(\%)\end{array}$ \\
\hline Research group & 90 & $8(8.89)$ \\
Control group & 90 & $25(27.78)$ \\
$X^{2}$ & & 10.73 \\
$P$ & & $<0.05$ \\
\hline
\end{tabular}

TABLE 2: COMPARISON OF NIHSS SCORE OF TWO GROUPS BEFORE AND AFTER TREATMENT

\begin{tabular}{lccc}
\hline \multirow{2}{*}{ Group } & \multirow{2}{*}{$\begin{array}{c}\text { Case } \\
\text { number }\end{array}$} & \multicolumn{2}{c}{ NIHSS score } \\
\cline { 3 - 4 } & & $\begin{array}{c}\text { Before } \\
\text { treatment }\end{array}$ & $\begin{array}{c}\text { After } \\
\text { treatment }\end{array}$ \\
\hline Research group & 90 & $26.50 \pm 4.05$ & $10.23 \pm 1.25$ \\
Control group & 90 & $26.35 \pm 3.93$ & $16.70 \pm 2.09$ \\
$\mathrm{t}$ & & 6.95 & 9.36 \\
$\mathrm{P}$ & & $<0.05$ & $<0.05$ \\
\hline
\end{tabular}

Mean \pm standard deviation 
treatment for patients with ruptured intracranial aneurysm, the oxyhemoglobin in the cerebrospinal fluid cannot be fully removed, but accumulate in the subarachnoid cavity, accompanying with massive amount of oxyhemoglobin in the acute phase. This results in local and systemic inflammatory reactions, which activate a large number of inflammatory cells and platelets resulting in widespread thrombotic condition.

Nimodipine is a dihydropyridine calcium antagonist, which inhibits the voltage-gated calcium channel of vascular smooth muscle cells to cause arterial vasodilation. It can improve the symptoms of vasospasm and play a good role in preventing cerebral vasospasm $^{[9,10]}$. In addition, nimodipine can help to increase the diameter of small perforator arteries, and has more significant diastolic effect on small vessels

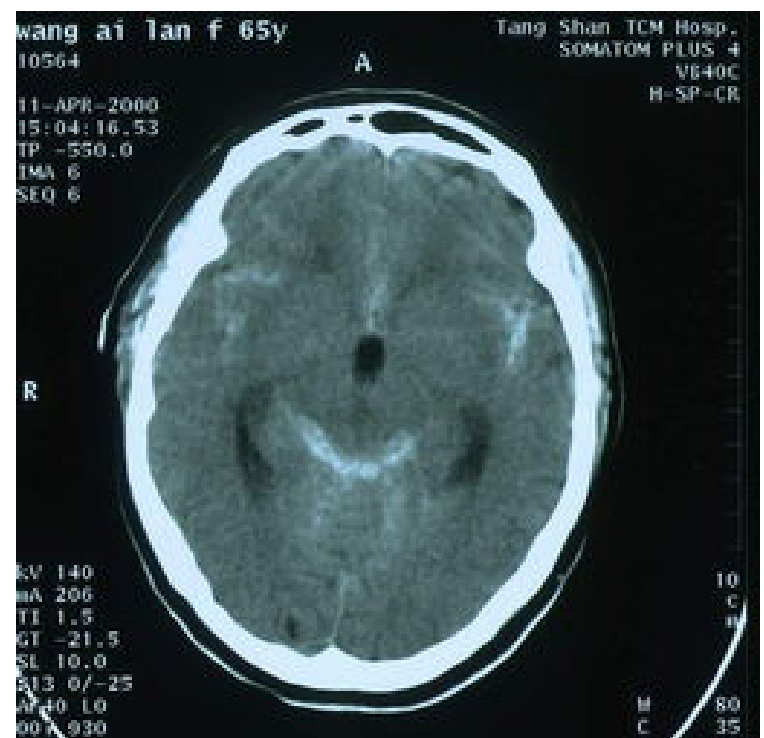

Fig. 2: Imaging examination of a patient

TABLE 3: COMPARISON OF CSF PRESSURE AND ERYTHROCYTE COUNT IN CSF BETWEEN TWO GROUPS

\begin{tabular}{|c|c|c|c|c|c|c|c|c|}
\hline \multirow[b]{2}{*}{ Group } & \multicolumn{4}{|c|}{ CSF pressure $\left(\mathrm{mmH}_{2} \mathrm{O}\right)$} & \multicolumn{4}{|c|}{ erythrocyte count in $\operatorname{CSF}(\times 109 /())$} \\
\hline & $\begin{array}{l}\text { Before } \\
\text { surgery }\end{array}$ & $\begin{array}{l}\text { Day } 4 \text { after } \\
\text { surgery }\end{array}$ & $\begin{array}{c}\text { Day } 8 \text { after } \\
\text { surgery }\end{array}$ & $\begin{array}{c}\text { Day } 12 \text { after } \\
\text { surgery }\end{array}$ & $\begin{array}{l}\text { Before } \\
\text { surgery }\end{array}$ & $\begin{array}{c}\text { Day } 4 \\
\text { after } \\
\text { surgery }\end{array}$ & $\begin{array}{c}\text { Day } 8 \\
\text { after } \\
\text { surgery }\end{array}$ & $\begin{array}{l}\text { Day } 12 \\
\text { after } \\
\text { surgery }\end{array}$ \\
\hline Research group $(n=90)$ & $290.4 \pm 22.8$ & $246.9 \pm 21.5$ & $202.3 \pm 18.6$ & $156.0 \pm 14.6$ & - & $128.4 \pm 11.9$ & $59.6 \pm 9.5$ & $23.6 \pm 5.3$ \\
\hline Control group $(n=90)$ & $291.5 \pm 20.8$ & $275.8 \pm 23.7$ & $245.0 \pm 19.5$ & $190.4 \pm 12.3$ & - & $130.6 \pm 12.5$ & $94.7 \pm 9.6$ & $38.9 \pm 5.5$ \\
\hline $\mathrm{t}$ & 0.24 & 18.39 & 25.66 & 11.50 & - & 0.16 & 10.33 & 12.85 \\
\hline $\mathrm{P}$ & $>0.05$ & $<0.05$ & $<0.05$ & $<0.05$ & - & $<0.05$ & $<0.05$ & $<0.05$ \\
\hline
\end{tabular}

Mean \pm standard deviation

A.
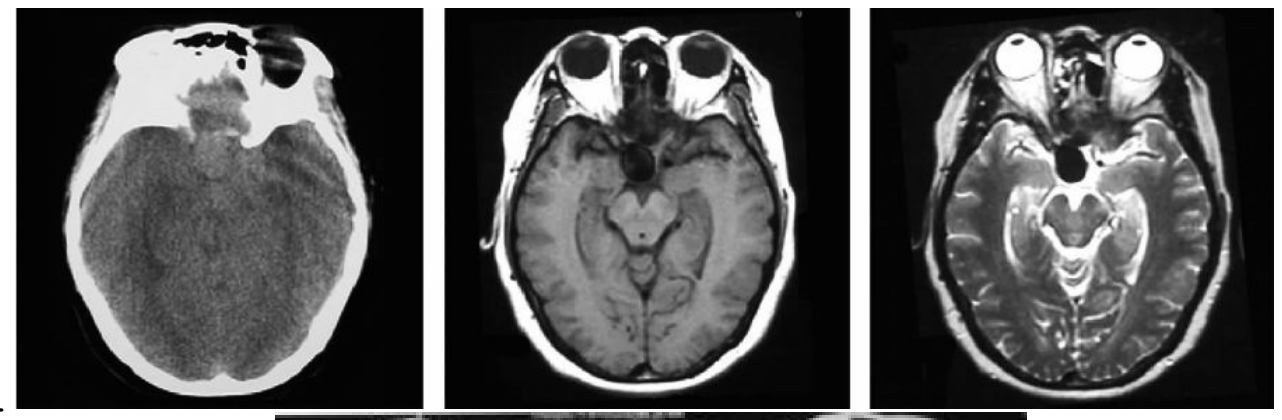

B.

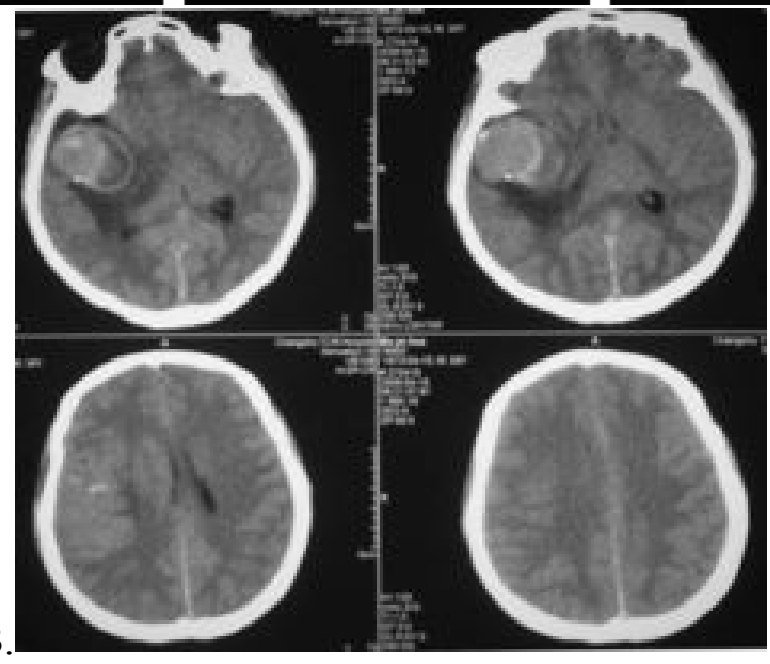

Fig. 3: Imaging examination (A) before treatment and (B) after treatment 
and thus improves brain microcirculation. For good prevention and treatment of postoperative cerebral vasospasm, effective cerebrospinal fluid drainage is essential under the premise of using nimodipine. Sustained lumbar cistern drainage in the early postoperative period can promote the early removal of toxic substances in cerebrospinal fluid, so as to prevent the occurrence of cerebral vasospasm ${ }^{[11-15]}$.

This study showed that the rate of cerebral vasospasm in the research group was significantly lower than that of control group $p<0.05$. On comparing the CSF pressure and erythrocyte count in CSF of both the groups before treatment and on days 4, 8 and 12 after treatment, both groups had significant improvement, but the improvement in the research group was greater $p<0.05$. By observing the degree of neural function defect in both the groups, it was found that the NIHSS score of the research group was significantly superior to that of control group, $\mathrm{p}<0.05$.

For patients with intracranial aneurysm interventional therapy, the application of lumbar cistern drainage combined with nimodipine produced greater remission with better safety. In this investigation, by adopting sustained lumbar cistern drainage combined with nimodipine and other conventional therapy, the cerebrospinal fluid pressure was reduced faster and cerebral vasospasm rate was effectively reduced. This indicated that sustained drainage significantly accelerated the clearance of hematocele, reduced the content of erythrocyte lysis products in cerebrospinal fluid and finally reduced the degree of vasospasm, which has better clinical effect than that of intermittent lumbar puncture combined with nimodipine. In addition, the therapeutic benefit in patients is not only reflected as a physical effect, but also in life quality, psychological function and social function. Therefore, future studies should pay attention to the effect of lumbar cistern drainage combined with nimodipine on the quality of life of patients with cerebral vasospasm after intracranial aneurysm intervention.

\section{REFERENCES}

1. Song Y, Dai H. Evaluation of application effect of sustained lumbar cistern drainage after intracranial aneurysm embolization. J Clin Med 2017;21(23):158-9.

2. Yang Z. Application of nimodipine combined with fasudil in treatment of cerebral vasospasm after intracranial aneurysm interventional embolization. Med Philosophy 2017;38(12):1820.

3. Zhuang J, Wang X. Effect of nimodipine combined with fasudil hydrochloride on cerebral vasospasm after SAC operation during acute hemorrhage of intracranial aneurysm. Hebei Med 2018;24(05):786-90.
4. Iwata H, Masuda N, Ohno S, Rai Y, Sato Y, Ohsui S, et al. A randomized, double-blind, controlled study of exemestane versus anastrozole for the first-line treatment of postmenopausal Japanese women with hormone-receptor-positive advanced breast cancer. Breast Cancer Res Treat 2016;139(2):441-51.

5. Lee DS, Kim SH, Kim S, Suh YJ, Kim HK, Shim BY. Prognostic significance of breast cancer subtype and p53 overexpression in patients with locally advanced or high-risk breast cancer treated using upfront modified radical mastectomy with or without post-mastectomy radiation therapy. Int J Clin Oncol 2017, 17(5): 447-455.

6. Wu Y, Yi T, Wang Z, Luo G, Wu B. Effect of lumbar cistern drainage combined with nimodipine on cerebral vasospasm after interventional treatment of intracranial aneurysm. Chin J Modern Drug 2018;12(12):34-36.

7. Jiang H. Observation of postoperative complications in patients with intracranial aneurysm embolization and Nursing treatment. Chin General Nurs 2016;14(15):1536-7.

8. Al-Aqeedi RF, Ali WM, Al-Ani F, Abdulrahman YS, Alnabti A. A blunt chest trauma causing left anterior descending artery dissection and acute myocardial infarction treated by deferred angioplasty. Heart Views 2017;12(2):369-374.

9. Vinz H, Festge OA, Neu J. Malpractice in the Treatment of Fractures and Dislocations of the Elbow Joint in Children Experience of the Arbitration Office of the North German Medical Boards. Z Orthop Unall 2016;150(01):98-112.

10. Liu H, Zhang H, Sun X, He Y, Li J, Guo X. A Cross-Sectional Study of Associations between Nonsynonymous Mutations of the BARD1 Gene and Breast Cancer in Han Chinese Women. Asia Pac J Public Health 2013;254(S4SI): 8S-14S.

11. Gao W, Wang Y, Wang W, Shi L. The first multiplication atombond connectivity index of molecular structures in drugs. Saudi Pharm J 2017;25(4):548-55.

12. Rehman N, Orakzai MB, Hayat A, Azam S, Ahmad B, Khan I. Prevalence of Hepatitis $\mathrm{C}$ virus and its risk factors in blood donors in district Peshawar. Pak J Pharm Sci 2018;31(1):8387.

13. Paray BA, Al-Mfarij AR, Al-Sadoon M. Food habits of the Arabian skink, Scincus hemprichii Wiegmann, 1837, (Sauria: Scincidae), in the Southwest Saudi Arabia. Saudi J Biol Sci 2018;25(1):90-93.

14. Huang W, Ding L, Zhong H. Expression levels of net1, kai1/ CD82 proteins and D2-40 labeled lymphatic vessel invasion (LVI) in esophageal squamous cell carcinoma (ESCC) and their correlation with clinicopathological factors. Acta Medica Mediter 2017;33(2):223-29.

15. Erer OF, Erol S, Anar C, Biçmen C, Aydoğdu Z, Aktoğu S. The diagnostic accuracy of endobronchial ultrasound-guided transbronchial needle aspiration (EBUS-TBNA) in mediastinal tuberculous lymphadenitis. Turk J Med Sci 2017;47(6): 1874-9.

This is an open access article distributed under the terms of the Creative Commons Attribution-NonCommercial-ShareAlike 3.0 License, which allows others to remix, tweak, and build upon the work non-commercially, as long as the author is credited and the new creations are licensed under the identical terms

This article was originally published in a special issue: Special issue on "Drug Development and Human Health in China"

Indian J Pharm Sci 2020:82(1)spl issue2;58-62 